\title{
Flow Injection Analysis With Trimetazidine Dihydrochloride lon-Selective Electrode
}

\author{
Yousry M. Issa*, Nour T. Abdel-Ghani and Howayda M. Ahmed \\ Chemistry Department, Faculty of Science, Cairo University, \\ Cairo, Egypt.
}

\begin{abstract}
New Plastic membrane ion-selective electrode for trimetazidine dihydrochloride based on trimetazidinium-tetraphenylborate was prepared. The electrode exhibited mean calibration graph slope of $29.5 \mathrm{mV}$ per decade of $\left(\mathrm{TrimCl}_{2}\right)$ concentration at $25^{\circ} \mathrm{C}$. The electrode can be used within the concentration range $3.2 \times 10^{-5}-10^{-2} \mathrm{M}\left(\mathrm{TrimCl}_{2}\right)$ at $\mathrm{pH}$ ranges of 1.5-3.8 and 4.5-7.5. The standard electrode potentials were determined at different temperatures and used to calculate the isothermal coefficient of the electrode, which was $\left(0.00088 \mathrm{~V}^{\circ} \mathrm{C}^{-1}\right)$. The electrode showed a very good selectivity for $\left(\mathrm{TrimCl}_{2}\right)$ with respect to a number of inorganic cations, sugars and amino acids. The electrode was applied to the potentiometric determination of the trimetazidine ion and its pharmaceutical preparation under batch and flow injection conditions. Graphite coated wire was prepared and characterized as sensor for the drug under investigation. Also, trimetazidine was determined by conductimetric titrations.
\end{abstract}

\section{Keywords}

Trimetazidine ion-selective electrode, coated graphite-pencil rod, conductimetric titrations and flow injection analysis. 


\section{Introduction}

Trimetazidine dihydrochloride (Trim- $\left.\mathrm{Cl}_{2}\right)$; is 1-(2,3,4-Trimethoxy benzyl)piperazine dihydrochloride, mol. wt. 339.3, [CAS-13171-25-0]. It is used in angina pectories and in ischaemia of neurosensorial tissues as in Méniére's disease. Trimetazidine dihydrochloride has been<smiles>COc1ccc(CN2CCNCC2)c(OC)c1OC</smiles>

determined using a limited number of techniques including high performance thin layer chromatography [1], reversed phase liquid chromatography [2], liquid chromatography-mass spectrometry [3], voltammetry [4], spectrophotometry $[5,6]$ and gas chromatography-mass spectrometry [7]. Although there is an increased demand for chemical surveillance in different fields including, pharmaceutical and industries which has created the need for highly sensitive, selective, precise and inexpensive techniques; no ion-selective electrode (ISE) has been constructed for the determination of Trimetazidine dihydrochloride. In this study, plastic membrane electrode for Trim cation was constructed based on the incorporation of trimetazidinium tetraphenylborate (Trim-TPB) ion associate in poly (vinyl chloride) (PVC) membrane plasticized with dibutylphethalate (DBP). The electrode was fully characterized under batch conditions according to IUPAC recommendations [8] and then used to determine the drug both in batch and with a flow injection technique (FIA) in which calibration standards and samples are allowed to flow over the membrane surface of the sensing electrode coupled to a reference electrode. The FIA technique has been used in this work for assessing the possibility of using the method for measuring Trim cation. Based on the success of the conventional type Trim-TPB electrode, a fine graphite coated electrode for trimetazidine has also been prepared and investigated. 


\section{Experimental}

\section{Reagents}

All reagents used for the preparation of solutions were of analytical-reagent grade. Doubly distilled water was used for preparing solutions and as a flow stream in FIA measurements. The carrier and reagent solutions were degassed by means of vacuum suction. All sample solutions used for injections were freshly prepared prior to measurements. Pure grade trimetazidine dihydrochloride and its pharmaceutical preparation (Vastarel, $20 \mathrm{mg}$ per tablet) were provided by the Servier Egypt Industries Limited, $6^{\text {th }}$ of October City, Giza, Egypt. Sodium tetraphenylborate (NaTPB), and diobutyl phthalate (DBP) were obtained from Fluka. Poly (vinyl chloride) (PVC) of high molecular weight and tetrahydrofuran (THF) were obtained from Aldrich.

\section{Apparatus}

Potentiometric measurements were carried out with an LPH 230T-pH meter (Tacussel Electronique) (France). A Techne circulator thermostat, model C-100 (Cambridge Limited) (England), was used to control the temperature of the test solution. The electrochemical system was of a sequence:

Ag/AgCl/filling solution/membrane/test solution//KCl salt bridge//SCE.

The flow injection set-up is composed of a four channel peristaltic pump (ISM 827) (Ismatec, Zurich, Switzerland) and a Model 5020 injection valve with exchangeable sample loop from Rheodyne (Cotati, CA, USA). The electrode was connected to a WTW pMX 2000 microprcessor pH/ion meter and interfaced to a Model BD 111 strip chart recorder from Kipp and Zonn (Deflt, The Netherlands). A wall jet cell, providing a low dead volume, fast response, good wash characteristics, ease of construction and compatibility with electrodes of various shapes and sizes, was used in flow measurements, where a Perspex cup with axially positioned inlet polypropylene tubing was mounted at the sensing surface of the electrode body. The optimized distance between the nozzle and the sensing surface of the electrode was $5 \mathrm{~mm}$; this provides the minimum thickness of the diffusion layer and 
consequently a fast response [9]. The ISE with flow cup, reference electrode (SCE) and the outlet tube were placed in a beaker, where the level of the solution was kept $1 \mathrm{~cm}$ above the electrode surface.

The conductivity in conductimetric titrations was measured with the aid of an Engineered Systems \& Designs [ESD] conductometer model 72 (Conductance/TDS) (USA) provided with conductivity cell of 1.000 cell constant.

\section{Preparation of the ion-associate}

The ion-associate trimetazidine tetraphenylborate (Trim-TPB) was prepared by the addition of $50 \mathrm{ml}$ of $10^{-2} \mathrm{~mol} \mathrm{l}^{-1}$ TrimCl $_{2}$ solution to $100 \mathrm{ml}$ of $10^{-2} \mathrm{~mol} \mathrm{l}^{-1}$ sodium tetraphenylborate solution. The precipitate was filtered, washed thoroughly with distilled water until chloride free and air-dried. The composition of the precipitate, as identified by elemental analysis was 1: 2; the obtained results showed good agreement with the calculated values. The percent values found are: C 81.8, H 5.9 and N 3.0 while the calculated values are: $C 82.1, H 6.2$ and N 3.1.

\section{Preparation of the electrode}

The electrode was constructed as previously described [10]. The membrane composition was studied by varying the percentages $(w / w)$ of the ion exchanger, PVC and DBP until optimum composition that exhibits the Nernstian behavior and the best performance characteristics is reached. The membrane was prepared by dissolving the required amounts of PVC, ion-associate and the plasticizer (DBP) in a $6.0 \mathrm{~cm}$ diameter Petri-dish containing $8.0 \mathrm{ml}$ of tetrahydrofuran (THF) (the total weight of the ingredients was $350 \mathrm{mg}$ ). The dissolved components being well mixed to ensure homogeneity of the membrane. The Petri dish was then covered with a filter paper and the solvent was left to evaporate in air. The prepared membrane was cut and glued, using PVC-THF paste, to the polished end of a plastic cap attached to a glass tube. The electrode body was filled with a solution that is $10^{-3}$ mol $\mathrm{l}^{-1}$ with respect to both $\mathrm{NaCl}$ and Trim- $\mathrm{Cl}_{2}$ and preconditioned by soaking in $10^{-3}$ mol ${ }^{-1}$ Trim- $\mathrm{Cl}_{2}$ solution. 
For the preparation of the wire coated electrode, a graphite pencil rod, $(3 \mathrm{~mm}$ in diameter and $12 \mathrm{~cm}$ in length) is used. The rod is enclosed in a polyethylene tube of a proper diameter leaving $2.0 \mathrm{~cm}$ bared at both ends. One of these terminals was used for connection while the other was dipped in a solution made by dissolving the required amounts of the ion-associate, DBP and PVC in about $4 \mathrm{ml}$ of THF contained in a test tube. The plastic layer formed on the surface of the rod is left to dry in air and the process was repeated several times (10-15) till a layer of proper thickness is formed covering the terminal of the rod. The electrode did not need to be soaked in the respective drug solution before use.

\section{General procedure for conductimetric measurements}

Volumes containing $10-100 \mathrm{mg} \mathrm{TrimCl}{ }_{2}$ was transferred to a $50 \mathrm{ml}$ volumetric flask and made to the mark with bidistilled water. The contents of the volumetric flask were transferred to a beaker and the conductivity cell was immersed. Then $10^{-}$ ${ }^{2} \mathrm{M}$ NaTPB solution was added from a microburette and the conductance was measured subsequent to each addition of the reagent solution after thorough stirring. The conductance reading, taken 1-2 min, after each addition was corrected for dilution [11] by means of the following equation:

$$
\left.\Omega_{\text {corr }}=\Omega_{\text {obs }}\left[\left(v_{1}+v_{2}\right)\right] / v_{1}\right]
$$

where $\Omega$ is the electrolytic conductivity, $v_{1}$ is the initial volume $(50 \mathrm{ml})$ and $v_{2}$ is the volume of the added reagent (corr., corrected; obs., observed). A graph of corrected conductivity versus the volume of the titrant added was constructed and the end point was determined. One millilitre of $10^{-2} \mathrm{M} \mathrm{NaTPB}$ is theoretically equivalent to $1.7 \mathrm{mg}$ trimCl $\mathrm{Cl}_{2}$.

\section{Solubility Product of the Trim-TPB ion-associate}

The determination of the solubility product of the precipitate is important, since its reciprocal value is approximately equal to the equilibrium constant of the precipitation reaction leading to the formation of the ion-associate. If the ionassociate is sparingly soluble (highly hydrophobic), it is expected that its leaching to 
the aqueous bathing solutions, which is the main determining factor in the life time of the electrode, is very slow. The solubility product of the Trim-TPB precipitate was determined conductimetrically, as previously described [12] and was found to be $3.75 \times 10^{-17}$. This value indicates that the solubility of the ion-associate is very low $\left(2.1 \times 10^{-6} \mathrm{~mol} / \mathrm{l}\right)$. Consequently, the equilibrium constant of the reaction,

$$
\operatorname{TrimCl}_{2}+2 \mathrm{Na}-\mathrm{TPB}=\operatorname{TrimTPB}+2 \mathrm{NaCl}
$$

is $2.67 \times 10^{16}$, which reflects that the reaction is more than $99.9 \%$ complete. In the above equilibria, the solubility of the undissociated ion-associate in water (i.e. the intrinsic solubility) was omitted as it only has a negligible contribution to the total solubility

\section{Results and discussion}

Optimization of the ISE in batch conditions

Composition of the membrane

Several membrane compositions were investigated in which the content of the Trim-TPB ion-associate ranged from 5.0 to $15.0 \%(w / w)$, the electrode was repeatedly prepared four times. The preparation process was highly reproducible as revealed from the low standard deviation (RSD) values of the slopes obtained employing the prepared membranes (the mean RSD was about $0.86 \%$ ).

The best performance was obtained using composition $5.0 \%$ Trim-TPB, $47.5 \%$ PVC and $47.5 \%$ DBP, resulting in a slope of $29.52 \mathrm{mV}$ per concentration decade after minimum pre-soak time of $1 \mathrm{~h}$. The usable concentration range was $3.2 \times 10^{-5}-10^{-2} \mathrm{~mol} \mathrm{I}^{-1}$. The above composition was used to prepare membrane electrode for all further investigations.

\section{Effect of soaking}

The continuous soaking of the electrode in $10^{-3} \mathrm{~mol} \mathrm{I}^{-1} \mathrm{TrimCl}_{2}$ solution affects negatively its response to the trimetazidinium cation, which may be attributed to leaching of the active ingredients [ion-associate and solvent mediator] to the 


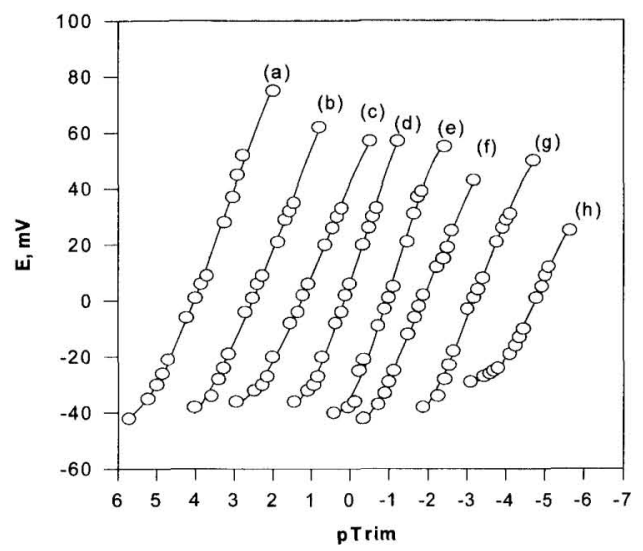

Fig.1. Calibration graphs obtained at $25^{\circ} \mathrm{C}$ after soaking Trim-TPB electrode for 1 (a), 3 (b), 9 (c) and $24 \mathrm{hrs}(\mathrm{d}), 2(\mathrm{e}), 4(\mathrm{f}), 6(\mathrm{~g})$ and 7 days $(\mathrm{h})$.

All graphs start from pTrim $=6$.

bathing solution [13]. It was observed that the slopes of the calibration graphs obtained using the pre-conditioned electrode decreased gradually starting from $29.5 \mathrm{mV}$ per concentration decade reaching about to $21.7 \mathrm{mV}$ per concentration decade within six days, Fig.1. It is noteworthy that the electrodes which have been kept dry in a dark closed vessel and stored in a refrigerator showed nearly constant slope value and the same response properties on daily use extending to about 10 days. Hence it is recommended that unused electrodes be kept dry in a closed vessel in a refrigerator in order to extend its life spans substantially.

For the coated graphite electrode, it has been found that the plastic coat of the ionassociate must be reformed prior to every use, this is accomplished by immersing 
the bared terminal of the electrode in the solution mixture containing the Trim-TPB ion-associate, PVC and DBP for a few seconds and then drying it. This regeneration process proved to activate the membrane surface for 48 hours. The usable concentration range was $3.1 \times 10^{-5}-10^{-2} \mathrm{~mol} \mathrm{l}^{-1}$ and the slope was $29.35 \mathrm{mV}$ per concentration decade. Also the electrode does not need conditioning before each use.

\section{Effect of temperature of the test solution}

Calibration graphs [cell potential $\left(E_{\text {cell }}\right)$ versus pTrim] were constructed at different test solution temperatures $\left(25,35,45,50,55,60\right.$ and $\left.65^{\circ} \mathrm{C}\right)$ for the

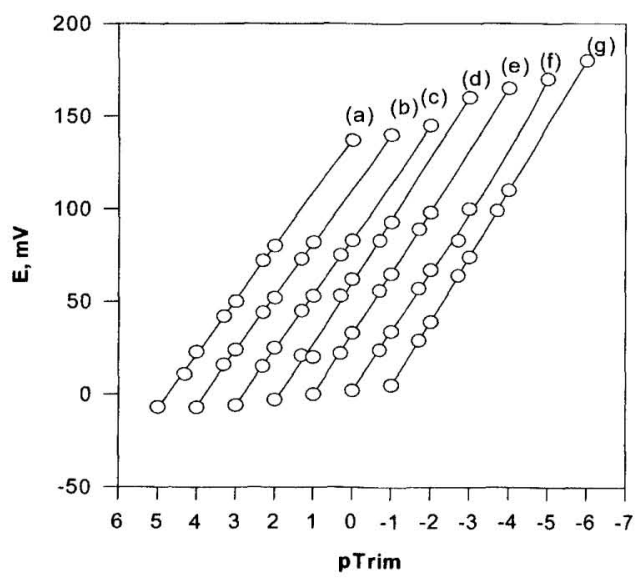

Fig.2. Calibration graphs for Trim-TPB electrode at test solution temperatures 25 (a), 35 (b) $45(\mathrm{c}), 50(\mathrm{~d}), 55(\mathrm{e}), 60(\mathrm{f})$ and $65^{\circ} \mathrm{C}(\mathrm{g})$.

All graphs start from $\mathrm{pTrim}=6$. 
electrode, Fig 2. The slopes, the usable concentration range and the standard cell potentials $\left(E^{\circ}\right)$ at different temperatures were obtained from the calibration graphs, as the intercepts at $\mathrm{p}$ Trim $=0$ are given in table 1 .

The results showed that within the investigated temperature range, the electrode respond, in practice, to $\left(\mathrm{Trim}-\mathrm{Cl}_{2}\right)$ with a nearly

\begin{tabular}{|c|c|c|c|c|c|c|}
\hline Electrode & $\begin{array}{c}\text { Temperature } \\
\left({ }^{\circ} \mathrm{C}\right)\end{array}$ & \multicolumn{2}{|c|}{$\begin{array}{c}\text { Slope (mV/decade) } \\
\text { Found Theoretical }\end{array}$} & $\begin{array}{c}\text { Concentration } \\
\text { Range }(\mathrm{M})\end{array}$ & $\begin{array}{c}\mathrm{E}^{\circ} \text { cell } \\
(\mathrm{mV})\end{array}$ & $\begin{array}{c}\mathrm{E}^{\circ} \text { ele } \\
\mathrm{c.} \\
(\mathrm{mV})\end{array}$ \\
\hline & 25 & 29.52 & 29.5 & $1.0 \times 10^{-5}-10^{-2}$ & 124 & 368 \\
\hline & 35 & 30.45 & 30.50 & $1.0 \times 10^{-5}-10^{-2}$ & 139 & 385 \\
\hline & 45 & 31.36 & 31.50 & $1.0 \times 10^{-5}-10^{-2}$ & 144 & 375 \\
\hline & 50 & 31.82 & 32.00 & $1.0 \times 10^{-5}-10^{-2}$ & 157 & 385 \\
\hline & 55 & 32.60 & 32.50 & $1.0 \times 10^{-5}-10^{-2}$ & 163 & 387 \\
\hline & 60 & 32.90 & 33.00 & $1.0 \times 10^{-5}-10^{-2}$ & 166 & 387 \\
\hline & 65 & 35.20 & 33.5 & $1.0 \times 10^{-4}-10^{-2}$ & 180 & 398 \\
\hline
\end{tabular}

*calculated from Nernst equation at each temperature.

Tab.1. Performance characteristics of Trim-TPB electrode at different temperatures

constant usable concentration range of $10^{-5}-10^{-2} \mathrm{M}$. The results (Table 1) show that the obtained values are in good agreement with those theoretically calculated from Nernst equation at each temperature up to $60^{\circ} \mathrm{C}$ for the electrode. This reflects a thermodynamic stability of the exchange process occurring at the interfacial junction which separates the plastic network from the test solution till this temperature.

For the determination of the isothermal coefficients $(\mathrm{dE} / \mathrm{dt})$ of the electrode, the standard electrode potential $E^{\circ}$ elec. corresponding to each temperature is calculated as the algebric sum of the cell potential and the potential of calomel electrode at the corresponding temperature and plotted versus ( $t-25)$, Table 1, 
where $\mathrm{t}$ is the temperature of the test solution in Celsius. A straight line is obtained according to Antropov's equation [14]:

$$
E=E^{\circ}{ }_{(25)}+\left(d E^{\circ} / d t\right)(t-25)
$$

The isothermal coefficient of the cell and the electrode are determined as the slope of the straight line obtained amounting to 0.00133 and $0.00088 \mathrm{VC}^{-1}$, respectively for Trim-TPB electrode. This reveals a fairly good thermal stability of the electrode within the investigated temperature range.

\section{Optimization of FIA response}

The flow injection measurements were carried out in a two-line configuration. The sample was injected into a distilled water stream, which was then merged with another stream of distilled water. In both lines the same tubing size was used, offering the same flow rate. The connector of the two streams was connected to the detector by a $50 \mathrm{~cm}$ tube of $0.4 \mathrm{~mm}$ internal diameter. Fig.3. shows the configuration of the system used in measurements. The dispersion coefficient was found to be 1.22 , i.e., limited dispersion coefficient that aids optimum sensitivity and fast response of the electrode [15].

\section{Sample,} $75 \mu \mathrm{l}$

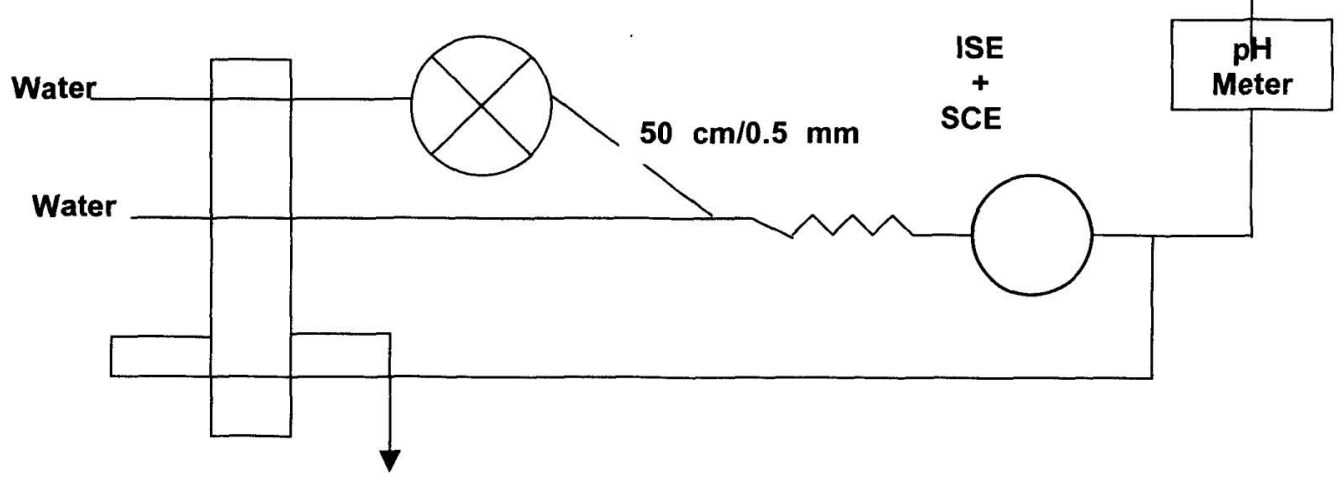

To Waste

Fig. 3. Schematic diagram of the flow injection system used in measurements. 


\section{Optimization of operational conditions of FIA}

Optimization of flow rate and sample volume.

Samples of different volumes $(5-340 \mu l)$ were injected. In general, the higher the sample volume, the higher is the peak height and the longer is the residence time of the sample at the electrode surface, requiring a longer time to reach a steady state and greater consumption of sample [16]. A sample loop of size $75 \mu \mathrm{l}$ was used through out this work, giving about $99 \%$ of the maximum peak height obtained by a $340 \mu \mathrm{l}$ loop but with a shorter time to reach the baseline and less consumption of reagents. The response of the Trim-TPB electrode was studied at different flow rates $(4.15,5.35,7.50,9.70,12.50,17.85,23.25,25.00,27.00$ and $30.00 \mathrm{ml} \mathrm{min}^{-1}$ ) with a constant injection volume. The residence time of the sample was inversely proportional to the flow rate [17] while the recovery time was linearly proportional to the residence time of the sample at the active membrane surface. It was found that, as the flow rate increased, the peaks becomes higher and narrower until a flow rate of $25.00 \mathrm{ml} \mathrm{min}^{-1}$ was reached, after which the peaks obtained at higher flow rates were nearly the same. A flow rate of $9.7 \mathrm{ml} \mathrm{min}^{-1}$ was adopted, providing about $99 \%$ of the maximum peak height obtained by higher flow rates, a short time to reach the baseline and less consumption of the carrier.

\section{Optimization of $\mathrm{pH}$}

The effect of $\mathrm{pH}$ of the test solution on the electrode potential was studied in batch and FIA measurements. In batch measurements, the variation in potential with $\mathrm{pH}$ was followed by the addition of small volumes of $\mathrm{HCl}$ and $\mathrm{NaOH}(0.1-1.0$ mol r-1), whereas in FIA, a series of $10^{-2} \mathrm{~mol} \mathrm{l}^{-1} \mathrm{TrimCl}_{2}$ solutions of different $\mathrm{pH}$ ranging from 1.0 to 10.0 were injected into the flow stream and the peak heights, representing variation of potential response with $\mathrm{pH}$, were measured. It was evident that the electrode exhibits stability towards $\mathrm{pH}$ changes with the two $\mathrm{pH}$ intervals 1.5-3.8 and 4.5-7.5 in batch and 2.0-4.0 and 5.0-8.0 in FIA conditions. 
At $\mathrm{pH}$ less than 1.5, the increase in potential at this $\mathrm{pH}$ interval may be due to an additional potential arising from the interference of excessive hydronium ions present in the immediate vicinity of the membrane surface facing the bath solution. For gradual decrease in potential observed at a $\mathrm{pH}$-value more than 8.5 may be due to the deprotonation of $\mathrm{TrimCl}_{2}$ in the solution, leading to a consequent decrease in its concentration. Protonation constant of Trimetazidine has been determined by $\mathrm{pH}$-titration of $0.01 \mathrm{M}$ of its hydrochloride solutions with standard 0.1 $\mathrm{M} \mathrm{NaOH}$ solution. Titration curve of S-shape was obtained, the mean pKa values obtained was 4.2 and 7.3 indicating that the decrease in pH outside the above the working $\mathrm{pH}$-range is due to the formation of the free base.

\section{Electrode response in FIA}

In potentiometric detection, the electrode potential depends on the activity of the main sensed ion. This is considered to be a principle advantage of the present method. Also in flow measurements the dependence is semi- logarithmic over a wide analyte activity range according to the Nickolsky-Eisenman equation. However, the main unfavorable feature of the technique is the slow response of electrode potential to concentration change and this is pronounced when low concentrations are measured and depends on the state of the membrane surface at the interface with the measured solution [18]. This slow response is a fairly good reason for the super-Nernstian sensitivities obtained in FIA measurements. An increase in the slope of the calibration plots in FIA was observed compared with batch measurements, where potential is measured under conditions very close to the equilibrium at the membrane-solution interface [19]. The slope of the calibration graph was $33.9 \mathrm{mV}$ per concentration decade for Trim electrode. The usable concentration range of the electrode in FIA is $1.8 \times 10^{-5}-10^{-2} \mathrm{~mol} \mathrm{I}^{-1}$, which is slightly higher than in batch mode, mainly owing to the difference in the dispersion coefficients in the two techniques. 


\section{Selectivity of the electrode}

It was shown earlier for the solid state membrane electrodes that the apparent selectivity coefficient measured under transient flow injection conditions may differ significantly from that measured under batch conditions [20, 21]. This is interpreted by the difference in the time of interaction of the interferents with the membrane surface. This difference increases with increase in the interaction of the interferent with the membrane in comparison with the main sensed ion, and also the interference process is highly dependent on the rate of diffusion and the exchange reaction of the interfering ion [22]. Therefore, in FIA measurements, where the sample remains in contact with the electrode for a short period of time, the apparent selectivity should be different from that found in batch conditions.

The influence of some inorganic cations, amino acids and sugars on the Trim electrode was investigated. Under FIA conditions, the values of selectivity coefficients were calculated based on the potential values measured at the top of the peaks for the same concentrations of the drug and the interferent, whereas under batch conditions the separate solution method was applied and a high concentration of the interferent ion was applied and the same concentrations were used $\left(10^{-2} \mathrm{~mol} \mathrm{l}^{-1}\right)$ to ensure that there is no interference if lower concentrations than this are present. In this work, the mixed solution method was used for the determination the degree of tolerance towards sugars and amino acids.

The selectivity coefficients $\mathrm{K}_{T r i m, J^{2+}}^{\text {pot }}$ of the electrode, Table 2, reflect very high selectivity of the investigated electrode for trimetazidinium cation. The mechanism of selectivity is mainly based on the stereospecificity and electrostatic environment and it is dependent on how much fitting is present between the locations of the lipophilicity sites in the two competing species in the bathing solution side and those present in the receptor of the ion-associate [23]. The inorganic cations do not interfere because of the differences in ionic size, mobility and permeability. Also, the smaller the energy of hydration of the cation, the greater is the response of the membrane. The electrode exhibits good tolerance towards amino acids and sugars. 
Regarding the selectivity coefficients obtained for the investigated electrode under both batch and FIA conditions, Table 2, it is clear that in most cases, the electrode was selective in both FIA and batch.

Comparing the selectivity coefficients obtained for the investigated electrode under both batch and FIA conditions (Table 2), it is clear that in most cases, the electrode was selective both in FIA and in batch conditions.

\begin{tabular}{|c|c|c|c|}
\hline \multirow[b]{2}{*}{ Interferent } & \multicolumn{2}{|c|}{ Batch } & \multirow[b]{2}{*}{ FIA } \\
\hline & $\mathrm{SSM}^{2}$ & Tolerance & \\
\hline $\mathrm{NH}_{4}^{+}$ & $1.0 \times 10^{-3}$ & ------ & $2.2 \times 10^{-4}$ \\
\hline $\mathrm{Na}^{+}$ & $5.8 \times 10^{-3}$ & ------- & $6.3 \times 10^{-3}$ \\
\hline $\mathrm{Mg}^{2+}$ & $6.1 \times 10^{-5}$ & - -.--- & $6.0 \times 10^{-4}$ \\
\hline $\mathrm{Ni}^{2+}$ & $2.1 \times 10^{-4}$ & -.----- & $5.9 \times 10^{-4}$ \\
\hline $\mathrm{Zn}^{2+}$ & $2.9 \times 10^{-4}$ & --.-- & $6.0 \times 10^{-4}$ \\
\hline $\mathrm{Cu}^{2+}$ & $1.2 \times 10^{-4}$ & ------- & $6.4 \times 10^{-4}$ \\
\hline $\mathrm{Be}^{2+}$ & $6.8 \times 10^{-4}$ & -ב----- & $4.3 \times 10^{-4}$ \\
\hline $\mathrm{Ba}^{2+}$ & $6.3 \times 10^{-4}$ & ------- & $1.5 \times 10^{-4}$ \\
\hline $\mathrm{Pb}^{2+}$ & $5.4 \times 10^{-4}$ & ------ & $2.6 \times 10^{-4}$ \\
\hline $\mathrm{Sr}^{2+}$ & $1.8 \times 10^{-4}$ & -ב-.-- & $7.6 \times 10^{-4}$ \\
\hline $\mathrm{Co}^{2+}$ & $5.6 \times 10^{-4}$ & - -...-.- & $7.5 \times 10^{-4}$ \\
\hline $\mathrm{Al}^{3+}$ & $2.0 \times 10^{-4}$ & ------ & $1.8 \times 10^{-6}$ \\
\hline Glucose & -------- & 273 & - --- \\
\hline Fructose & -_--_--- & 470 & -.-_-_--- \\
\hline Maltose & - ----- & 221 & -...----- \\
\hline Lactose & ---------" & 254 & ---------- \\
\hline Ascorbic acid & ---------- & 161 & ---------- \\
\hline Vitamine $B_{1}$ & --------- & 204 & --------- \\
\hline Leucine & ------_--- & 146 & - \\
\hline Alanine & ---------- & 117 & -------- \\
\hline Glycine & 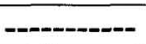 & 126 & -.------- \\
\hline
\end{tabular}

aSSM: separate solution method.

Tab. 2. Selectivity coefficients $\mathrm{K}_{T r i m, J^{2+}}^{\text {pot }}$ of the Trim-TPB responsive electrode

Conductimetric Determination of the Solubility Product of Trim-TPB ion associate

Two series of aqueous solutions of different concentrations (c) $\left(10^{-5}, 5 \times 10^{-5}\right.$, $10^{-4}, 5 \times 10^{-4}, 10^{-3}, 5 \times 10^{-2}$ and $10^{-2} \mathrm{M}$ ) were prepared for each of $\mathrm{TrimCl}_{2}$ and $\mathrm{NaTPB}$. 
The conductivities of these solutions were measured at $25^{\circ} \mathrm{C}$ and the specific conductivities $(K)$, corrected for the effect of the dilution of the different species, were calculated. They in turn were used to obtain the equivalent conductivities $(\lambda)$ of the species. Straight line plots of $\lambda$ versus $(c)^{1 / 2}$ were constructed and $\left(\lambda_{0} \operatorname{TrimCl}_{2}\right)$ and $\left(\lambda_{0} \mathrm{NaTPB}\right)$ were determined, from the intercepts of the respective lines with the $\lambda$-axis. The activity coefficients of the ions employed were taken as unity because all the solutions were sufficiently dilute $\left(10^{-5}-10^{-2}\right) \mathrm{M}$. The values of $\left(\lambda_{\circ}\right.$ Trim-TPB) were calculated from the values obtained for $\left(\lambda_{0} \operatorname{TrimCl}_{2}\right)$ and $\left(\lambda_{0} \mathrm{NaTPB}\right)$ with the aid of Kohlrausch's law of independent migration of ions. The solubility (S) and the solubility product (Ksp) of the ion-associate Trim-TPB were calculated using the following equation:

$$
S=K s \times 1000 /\left(\lambda_{0} \text { Trim-TPB }\right) \text { and } K s p=4 S^{3}
$$

where $\mathrm{Ks}$ is the specific conductivity of a saturated solution of the ion-associate, determined at $25^{\circ} \mathrm{C}$. The saturated solution was made by stirring a suspension of the solid precipitate in distilled water for $3 \mathrm{hrs}$. at $25^{\circ} \mathrm{C}$.

\section{Analytical applications}

$\mathrm{TrimCl}_{2}$ was determined potentiometrically using the investigated conventional electrode and graphite coated wire under batch conditions by standard additions method [24], where the direct potentiometric method led to the formation of Trim-TPB precipitate which renders end point detection. In which a small portions of standard $0.01 \mathrm{M}$ of $\mathrm{TrimCl}_{2}$ was added to $50 \mathrm{ml}$ of water containing $10-100 \mathrm{mg}$ of pure compound or its equivalent from pharmaceutical preparation. The change in millivolt readings was recorded after each addition and used to calculate the concentration of the $\mathrm{TrimCl}_{2}$ sample solution. For sampling of tablets (Vastarel, $20 \mathrm{mg}$ per tablet), 20 tablets were ground together and appropriate weights of drug containing tablet were dissolved in the equivalent volume of $0.01 \mathrm{M} \mathrm{HCl}$ and diluted to $50 \mathrm{ml}$ with bidistilled water. 
For batch method, the mean recoveries of the amounts taken (10-100 $\mathrm{mg}$ ) ranging from $97.1-99.7 \%$ with RSD $=0.14-1.07 \%$ (Table 3 ).

For graphite-pencil rod, the mean recoveries of the amounts taken (10-100 $\mathrm{mg}$ ) ranging from $98.3-101.5 \%$ with $\mathrm{RSD}=0.31-1.5 \%$ (Table 3 ).

The results of the determination of trimetazidine in its pure state or pharmaceutical preparation by conductimetric method are given in Table 3. The results showed good recovery of the amounts taken (10-100 $\mathrm{mg}$ ) ranging from 96.9 to $101.2 \%$ with RSD $=0.25-1.4 \%$ (Table 3$)$.

Under FIA conditions, a series of solutions of different concentrations was prepared from the tablets and the peak heights were measured at the selected flow rate (9.7 $\mathrm{ml} \mathrm{min}^{-1}$ ), then compared with those obtained from injecting a standard solution of the same concentration prepared from pure trimetazidine dihydrochloride. The mean recoveries for the amounts taken $(10-100 \mathrm{mg}$ ) ranged from 96.9 to $100.9 \%$ with RSDs of $0.34-1.8 \%$. These methods are compared with each other by applying F- and t- tests [25] with the official method (potentiometric titration) [26]. The values given in Table 4, show that the present methods are of comparable precision to each other and there is no significant difference between the mean values obtained by the three methods. 


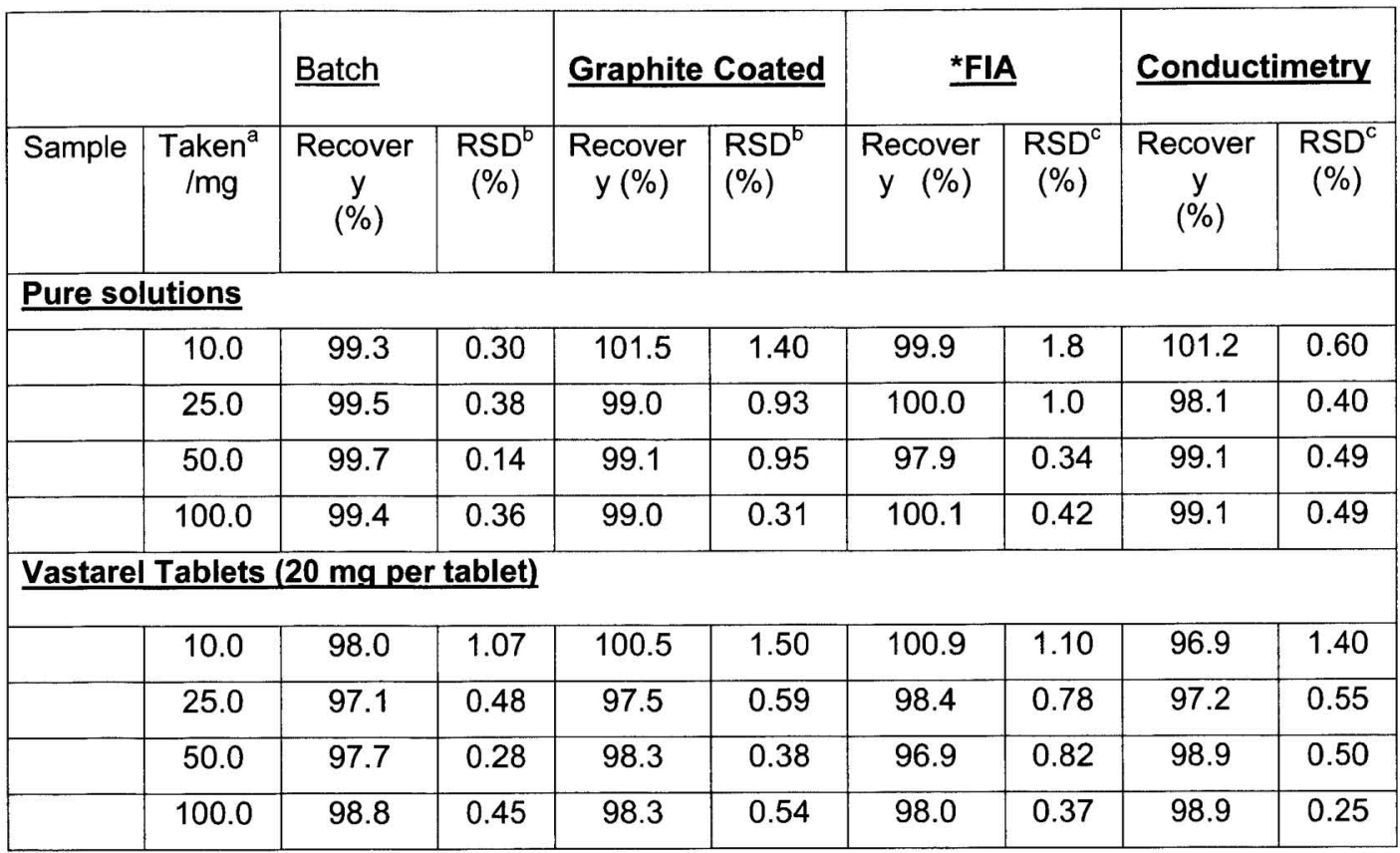

${ }^{a}$ Taken $\mathrm{mg}$ per $50 \mathrm{ml}$. ${ }^{\mathrm{b}}$ Four determinations. $\quad{ }^{\mathrm{c}}$ Three determinations.

*Flow rate $9.7 \mathrm{ml} / \mathrm{min}^{-1}$.

Tab. 3. Determination of Trimetazidine dihydrochloride by conductimetry and by employing the Trim-TPB electrode and graphite coated applying the standard additions method under batch and FIA conditions 


\begin{tabular}{|c|c|c|c|c|c|}
\hline & \multirow{2}{*}{$\begin{array}{l}\text { Official } \\
\text { method }\end{array}$} & \multicolumn{4}{|c|}{ Proposed method } \\
\hline & & Batch & $\begin{array}{c}\text { Graphite } \\
\text { coated }\end{array}$ & FIA & $\begin{array}{c}\text { Conductimetr } \\
y\end{array}$ \\
\hline \multicolumn{6}{|c|}{ Pure solutions } \\
\hline$X \pm S E$ & $98.8 \pm 0.26$ & $99.5 \pm 0.14$ & $99.6 \pm 0.29$ & $99.5 \pm 0.26$ & $99.4 \pm 0.22$ \\
\hline Probability & & $>0.05$ & $<0.05$ & $<0.05$ & $<0.05$ \\
\hline Relative error & 0.15 & 0.50 & 0.36 & 0.50 & 0.58 \\
\hline $\begin{array}{l}F^{3,3} \text { value } \\
(9.27)^{a}\end{array}$ & & 3.4 & 1.2 & 1.0 & 1.3 \\
\hline \multicolumn{6}{|c|}{ Vastarel Tablets } \\
\hline$X \pm S E$ & $98.2 \pm 0.13$ & $97.92 \pm 0.20$ & $98.6 \pm 0.26$ & $98.6 \pm 0.27$ & $97.96 \pm 0.19$ \\
\hline Probability & & $>0.01$ & $>0.01$ & $>0.01$ & $>0.01$ \\
\hline Relative error & 1.83 & 2.12 & 1.42 & 1.42 & 2.08 \\
\hline $\begin{array}{l}F^{3,3} \text { value } \\
(9.27)^{a}\end{array}$ & & 2.5 & 4.0 & 4.5 & 1.8 \\
\hline
\end{tabular}

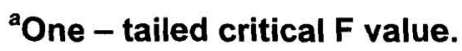

Tab. 4. Statistical treatment of data obtained for the determination of trimetazidine using Trim-TPB electrode and graphite coated rod in comparison with the official method. 


\section{Conclusion}

The application of the proposed methods usingTrim-TPB electrode under batch and FIA conditions in addition of conductimetric titration for determination of trimetazidine dihydrochloride in pure Solution and its pharmaceutical preparation (Vastarel, $20 \mathrm{mg} /$ tablet) are characterized by high degree of precision and accuracy when compared with the official method (potentiometric titration of $0.01 \mathrm{M}$ $\mathrm{TrimCl}_{2}$ with $0.1 \mathrm{M}$ silver nitrate) as revealed by one tailed $\mathrm{F}$ critical value, Table 3 . It is clear that the applied methods do not exhibit significant differences in comparison with the official method. The standard additions method and conductimetric titrations take about $15-20 \mathrm{~min}$ in each run. In addition, the FIA conditions shortened the time needed for the determination of the drug in pure state or its pharmaceutical preparation. Therefore, FIA is mostly recommended for determination of trimetazidine and its pharmaceutical preparations.

\section{References}

[1] Thoppil S O, Cardoza R M, Amin P D.

Stability Indicating HPTLC Determination of Trimetazidine as Bulk Drug and in Pharmaceutical Formulations.

Pharm. Biomed. Anal. J., 2001;25:15-20.

[2] Thoppil S O, Amin P D.

Trimetazidine: Stability Indicating Reverse-Phase (RP) LC Assay Method.

Pharm. Biomed. Anal. J.,2001;25:191-5.

[3] De Jager A D, Sutherland F C W, Badenhorst D, Hundt H K L, Swart J, Scanes T, Hundt A F.

High Throughput Assay for The Quantitation of Trimetazidine in Human Plasma by LC-MS, With Selected lon Monitoring.

Liq. Chromatogr. Relat. Technol. J.,2001;24:2121-32.

[4] Ghoneim M M, Khashaba P Y, Beltagi A M.

Determination of Trimetazidine Hydrochloride by Adsorptive Stripping Square- Wave Voltammetry at a Glassy Carbon Electrode. Pharm. Biomed. Anal. J.,2002;27:235-41.

[5] Issa Y M, Abou-Attia F M, Abdel-Gawad F M, Abdel-Hamid S M.

Utility of Some $\pi$-acceptors for the Spectrophotometric Determination of Trimetazidine Hydrochloride.

Anal. Lett.,2002;35:451-61. 
[6] Fay L, Michel G Goupit P, Harpey C, Prost M.

Determination of Trimetazidine in Biological Fluids by Gas Chromatography-Mass Spectrometry.

Pharm. Biomed. Appl. J.,2002; 82(1 J. Chromatogr.).

[7] Murthy T K, Sankar Gowri D, Rao Y S.

Visible Spectrometric Methods for the Determination of Trimetazidine Dihydrochloride in Pharmaceutical Formulations.

Indian Drugs,2002; 39: 230-33.

[8] Buck R P, Linder E.

Recommendations for Nomenclature of Ion-selective Electrodes. Anal. Chem., 1994;66: 2527-36.

[9] Gunasingham $\mathrm{H}$, Fleet B.

Wall-Jet Electrode in Continious Voltammetry.

Anal. Chem.,1983; 55: 1409-14.

[10] Abdel-Ghani N T, Hussein S H.

Determination of Ambroxol Hydrochloride in Pure Solutions and Some of its Pharmaceutical Preparations under Batch and FIA Conditions.

IL FARMACO,2003; 58: 581-9.

[11] Issa Y M Shoukry A F, El-Nashar R M.

Conductimetric Determination of Reproterol $\mathrm{HCl}$ and Pipazethate $\mathrm{HCl}$ and Sulbutamol sulphate in Their Pharmaceutical Formulations. Pharm.

Biomed. Anal. J.,2001; 26: 379-86.

[12] Shoukry A F, Abdel-Ghani N T, Issa Y M, Ahmed H M.

Plastic Membrane Selective Electrode for Cetirizinium Ion Based on Cetirizinium tetraphenylborate Ion-pair.

Electroanalysis, 1999; 11: 443-6.

[13] Linder $E$, Toth $K$, Pungor $E$.

Dynamic Characteristics of Ion-Selective Electrodes. Chemical Rubber Company, CRC Press, Boca Raton, USA,1988.

[14] Oesch V, Ammann D, Simon W.

Ion-Selective Membrane Electrodes for Clinical Use.

Clin. Chem., 1986;32:1448-1459.

[15] Trojanowicz M, Matuszewski W.

Limitation of Linear Response in Flow Injection Systems with Ion Selective Electrodes.

Anal. Chim. Acta, 1982;138: 71-9.

[16] Yang X, Hibbert D B, Alexander P. W.

Flow Injection Potentiometry by Polyvinyl Chloride Membrane Electrodes with Substituted Azocrown lonophores for the Determination of Lead (II) and Mercury (II) lons.

Anal. Chim. Acta, 1998;372: 387-98.

[17] Frenzel W, Bratter P.

The Fluoride Ion-selective Electrode in Flow Injection Analysis. Anal. Chim. Acta, 1986;188: 151-64. 
[18] Morf W E, Linder E, Simon W.

Theoritical Treatment of the Dynamic Response of lon-Selective Membrane Electrodes. Anal. Chem.1975;47:1489-91.

[19] Ilcheva L, Trojanowicz M, Vel Krawczyk T K, Fresenius' Z. Effect of Addition of Main Ion to Carrier Solution in Potentiometric Flow Injection Measurements with Solid State Ion-Selective Electrodes.

Anal. Chem., 1987;328: 27-32.

[20] Trojanowicz M, Matuszewski W.

Potentiometric Flow Injection Determination of Chloride.

Anal. Chim. Acta, 1983;151: 77-84.

[21] Davey D E, Mulcahy D E, O'Connel G R, Smart R S.

Comparison of Detector Cell Configuration in Flow Injection Potentiometry.

Electroanalysis, 1995; 7: 461-70.

[22] Hulanicki A, Lewenstam A.

Model for Treatment of Selectivity Coefficients for Solid-State IonSelective Electrodes.

Anal. Chem.,1981;53:1401-5.

[23] Abdel Ghani N T, Rizk M S, El-Nashar R M.

Potentiometric Flow Injection Determination of Salbutamol.

Analyst,2002;35: 39-52.

[24] Baumann E W.

Determination of Free Acid by Standard Addition Method with Potassium Thiocyanate as a Complexant.

Anal. Chem., 1984;56: 682-5.

[25] Miller J C, Miller J N, Editors

Statistics for Analytical Chemistry,

New Yourk: John Wiley\& Sons 1984.

[26] European pharmacopoeia, $4^{\text {th }}$ Edn., 2002, 207-5. 